\title{
CORRIGENDA
}

\section{Genetic epidemiology, prevalence, and genotype- phenotype correlations in the Swedish population with osteogenesis imperfecta}

Katarina Lindahl, Eva Åström, Carl-Johan Rubin, Giedre Grigelioniene, Barbro Malmgren, Östen Ljunggren and Andreas Kindmark

European Journal of Human Genetics (2015) 23, 1112; doi:10.1038/ejhg.2015129

Correction to: European Journal of Human Genetics (2015) 23, Post online publication, the authors have chosen to add some information 1042-1050; doi: 10.1038/ejhg.2015.81; published online 6 May 2015 to Supplementary Tables 1 and 2. The original files have been replaced with their updated counterparts and are available to view online.

\section{A prospective cohort study assessing clinical referral management \& workforce allocation within a UK regional medical genetics service}

Caroline Benjamin, Catherine Houghton, Claire Foo, Chris Edgar, Gail Mannion, Jan Birch, Ian Ellis and Astrid Weber

European Journal of Human Genetics (2015) 23, 1112; doi:10.1038/ejhg.201582

Correction to: European Journal of Human Genetics (2015) 23, 996-1003; doi:10.1038/ejhg.2015.33; published online 11 March 2015
Corrections have been made to Figure 1 and a revised copy of this paper appears in this issue.

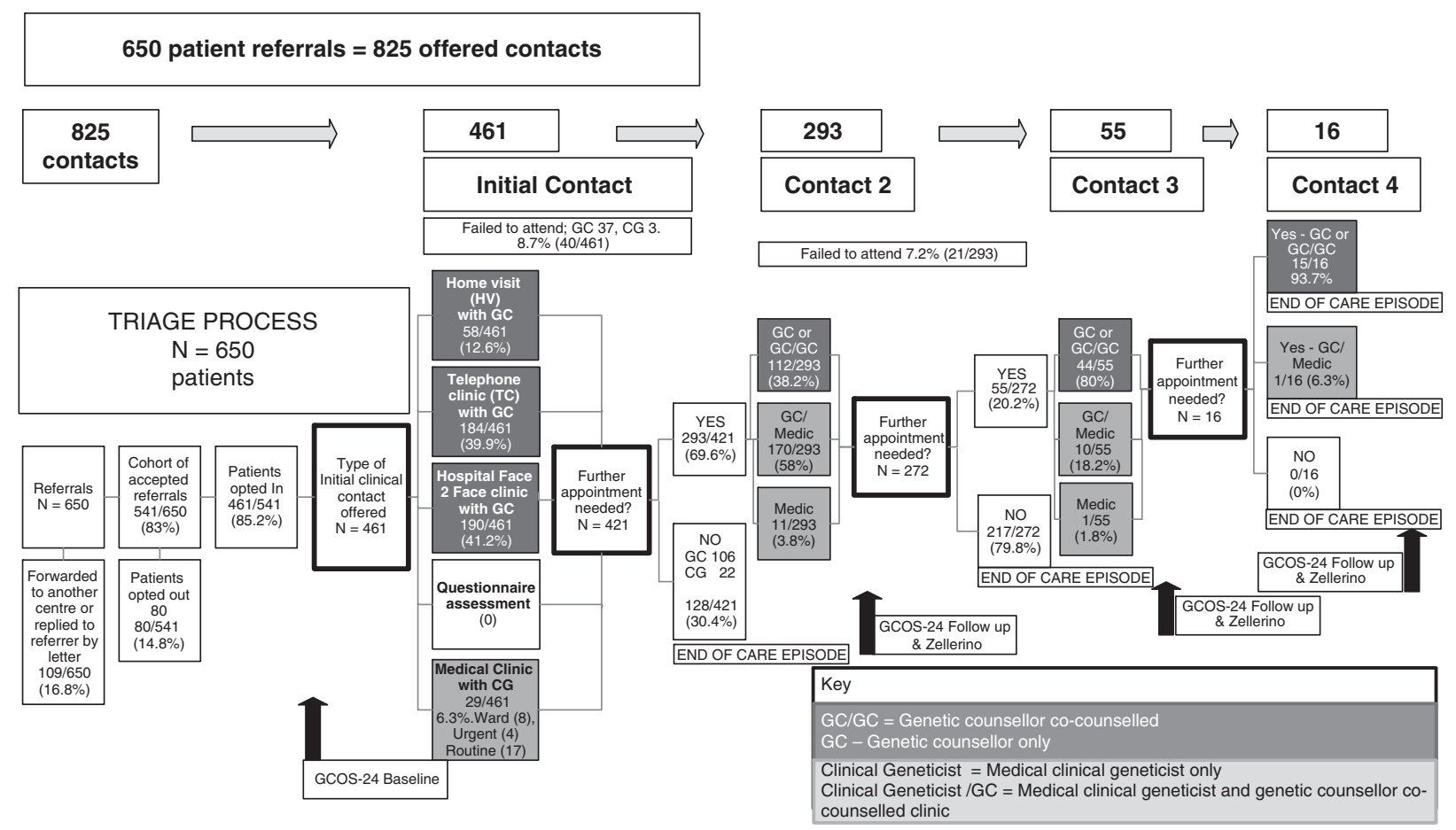

Figure 1 Progress of the 650 new patients referred over the 3-month period (12.12.2011-12.03.2012), resulting in 825 offered contacts - with 12 months of follow-up until 12.03.2013. 